\title{
El plan general sobre el turismo de andalucía
}

\author{
$M^{\underline{a}}$ Isabel Jáimez Gago
}

Doctora en Derecho por la Universidad de Málaga

Becaria de Investigación de la Junta de Andalucía

SUMARIO: 1. INTRODUCCIÓN. 2. LA PLANIFICACIÓN DEL TERRITORIO TURÍSTICO EN LAS DIFERENTES COMUNIDADES AUTÓNOMAS. 2.1. Peculiaridades del hecho insular. 2.1.A) Baleares. 2.1.B) Canarias. 3. EL PLAN GENERAL SOBRE EL TURISMO EN ANDALUCÍA. 4. PROCEDIMIENTO DE ELABORACIÓN DEL PLAN GENERAL DEL TURISMO. 5. ESTRUCTURA Y CONTENIDO DEL PLAN GENERAL DEL TURISMO DE ANDALUCÍA. 5.1. Primera parte del Plan. 5.1.A) Realizar análisis de la evolución y de la actual situación del turismo en Andalucía. 5.1.B) El Turismo en la economía andaluza. 5.1.C) Análisis de la demanda del turismo y sus tendencias. Análisis de la oferta.. a) Las tendencias envolventes. b) Las tendencias internas. c) Mercados emisores y receptores. d) Evolución y situación actual del turismo en Andalucía. e) Análisis de la oferta turística. f) Territorio y sostenibilidad. 5.2. Segunda parte del Plan. 5.2.A) Promoción. 5.2.B) Ordenación de recursos. 5.2.C) Fortalecimiento del tejido empresarial y creación de empleo. 5.2.D) Dependencia estacional. 5.1.E) Objetivo finalista del Plan General de Turismo. 6. OBJETIVOS a conseguir por el Plan General del Turismo en Andalucía. 7. REFLEXIÓN FINAL

\section{INTRODUCCIÓN}

La planificación turística en España viene a suponer un instrumento de fomento de valor incalculable para la consecución de la calidad del turismo tan reclamada hoy, tanto desde el sector público como desde el sector privado de nuestro país. Ahora bien, tal como parece obvio señalar, los servicios turísticos son múltiples debido a la propia naturaleza de los mismos, por lo que la actividad administrativa encaminada a la consecución de la planificación de estos, dependerá de los objetivos que se pretendan conseguir en cada momento, y de los criterios y contenidos de los instrumentos empleados para su consecución. Podemos decir por tanto, que del conjunto de actividades públicas llevadas a cabo por la Administración en nuestro país sobre el sector turístico, quizás sea la actividad planificadora la que tenga una mayor relevan- 
cia, ya que es sabido que el turismo es una materia multidisciplinar en la que confluyen un cúmulo de intereses y factores, y por consiguiente, las competencias sobre el mismo recaen sobre el conjunto de Administraciones públicas -Estado, Comunidades Autónomas y Administración Local- con los consiguientes problemas competenciales de toda índole que esto conlleva.

La ordenación territorial de las zonas turísticas se ha convertido sin duda en uno de los temas políticos y jurídicos de más relevancia en todas las regiones turísticas españolas, y especialmente en las Comunidades mediterráneas e insulares. Esto se hace patente debido a varios condicionantes fundamentales: la gran afluencia de turistas a esas zonas, unido a la intensa densidad poblacional existente en las mismas; la constante presión edificatoria para uso de alojamientos turísticos y de segundas residencias; y el fuerte ritmo de desarrollo de esas Comunidades, y por consiguiente, la escasez de territorio en las mismas, entre otros problemas ${ }^{1 .}$ De ahí que la actividad planificadora como actividad administrativa que es, con naturaleza muy dispar entre unos $u$ otros instrumentos de los que dispone para su consecución, pueda ubicarse en objetivos turísticos también muy dispares y diferentes entre sí.

Hay Planes autonómicos cuyo objetivo fundamental lo constituye el fomento de la formación; otros, cuyo objetivo se ajusta más a la búsqueda de la mejora de la organización territorial o de las condiciones medio-ambientales en las que se desarrolla la empresa turística. Otros instrumentos pretenden la mejora de la calidad en la prestación del servicio turístico a través de la innovación o tecnificación ${ }^{2}$, de tal forma que, la actividad administrativa de planificación, al margen de su mayor o menor valor reglamentario, pretende constituir en la práctica el marco para el desarrollo de otras múltiples intervenciones administrativas. Normalmente a través de los Planes se trata de fomentar o garantizar unas determinadas condiciones en la prestación del servicio turístico. En otras categorías se trata de establecer condiciones que, tras su desarrollo, den lugar a intervenciones más limitativas e incluso sancionadoras. Así pues, y como a continuación se indica, casi todas las Comunidades Autónomas prevén en sus Leyes de ordenación los concretos instrumentos de

\footnotetext{
${ }^{1}$ Vid: SOCÍAS CAMACHO, J. M. La ordenación de las zonas turísticas litorales. Instituto Pascual Madoz. Universidad Carlos III de Madrid, 2001. Boletín Oficial del Estado.

${ }^{2}$ Incluso, hay Planes, como ocurre con el el anterior Plan Marco de Competitividad del Turismo Español (FUTURES) -actualmente Plan Integral de Calidad del Turismo Español (PICTE)-, incardinados en la Administración General del Estado, que integran a su vez muchos de estos objetivos de forma conjunta.
} 
planificación turística que hayan de responder a los diferentes objetivos de política turística que en cada momento fije el Gobierno de dicha Comunidad Autónoma. ${ }^{3}$

En estos momentos, y desde febrero del 2003 que se aprobaron las Leyes de turismo de Navarra y Aragón, todas las Comunidades Autónomas cuentan ya con una Ley general sobre turismo propia ${ }^{4}$. En estas Leyes, lejos de existir un modelo único de planificación turística, cada una tiene un modelo distinto. Por tanto, la naturaleza de los instrumentos de planificación es ciertamente diferente de una a otra Ley, ya que en algunas, solo se contienen simples compromisos o programas de actuación (planes de obras públicas); en otras, sin embargo, existen compromisos con el sector privado en general, y definen una política económica indicativa no compulsiva (planes de desarrollo económico y social). Finalmente, hay que tener en cuente que los planes de urbanismo suponen concreciones limitadoras de derechos por vía reglamentaria, por lo que resultan incardinados en la actividad administrativa de limitación. ${ }^{5}$

Un breve repaso a la legislación autonómica permite advertir la comentada diversidad de instrumentos de planificación que, aunque con diferentes denominaciones, viene a englobar verticalmente las diferentes modalidades de estos, desde los Planes más generales, desde el punto de vista territorial y de su propia planificación, a los Planes más sectoriales como son los turísticos. ${ }^{6}$

\footnotetext{
${ }^{3}$ Vid. Fernández Rodríguez, Carmen. Documentación Administrativa / nº . 259-260 (enero-agosto, 2001)

${ }^{4}$ Excepción hecha de las Ciudades Autónomas de Ceuta y Melilla, condicionadas como estan por el desarrollo reglamentário de su régimen autonómico.

${ }^{5}$ Parada Vázquez, J.R., Derecho Administrativo. Parte General. Madrid, 2000, cit. pág. 403.

${ }^{6}$ Vid. Caballero Sánchez, R. Legislación sobre turismo. Ed. Mc Graw Hill. Madrid, 2000.
} 


\section{LA PLANIFICACIÓN DEL TERRITORIO TURÍSTICO EN LAS DIFERENTES COMUNIDADES AUTÓNOMAS ${ }^{7}$}

Entre las Comunidades Autónomas que actualmente cuentan con específicos instrumentos de planificación sobre el territorio turístico se encuentran:

Castilla y León: En esta Comunidad -Ley 10/1997, de 26 de mayo, de Ordenación del Turismo- la competencia de fomento y planificación turística se articula a través de la Dirección General de Turismo, bien de forma centralizada o bien a través de entes institucionales, contemplándose toda una serie de principios de planificación que han de informar a la planificación turística autonómica plasmada en el denominado Plan de Desarrollo Regional, cuyas características básicas son:

Ha de ser único y en el procedimiento de elaboración han de participar las Diputaciones Provinciales, los Municipios de más de dos mil habitantes, oyéndose al Consejo de Turismo, al Económico y Social, y a la Federación Regional de Municipios y Provincias; Se ha de coordinar con las actividades de la Agencia de Desarrollo Económico de Castilla y León y con los planes y programas de turismo de ámbito nacional o internacional; Ha de promover el desarrollo integral y sostenible; Ha de efectuar un seguimiento permanente y sistemático de sus programas y actuaciones; Ha de tener en cuenta los criterios generales de política económica, así como las determinaciones contenidas en los instrumentos de ordenación territorial y de protección de la naturaleza y los planes sectoriales con incidencia en el turismo; Será vinculante para la actuación de todas las Administraciones Públicas de la Comunidad e indicativo para la iniciativa privada.

La Ley de Ordenación -arts. 38 y siguientes- prevé los concretos instrumentos de desarrollo del Plan de Turismo a través de los denominados programas ejecutivos que pueden ser de varios tipos según los objetivos a los que se dirijan: Programas de diversificación de la oferta turística; Programas de calidad de la oferta turística; Programas de formación turística; Programas de promoción y difusión turística.

País Vasco: La Ley 6/1994, de 16 de marzo, de Ordenación del Turismo del País Vasco, determina que la Ordenación de los Recursos Turísticos se re-

\footnotetext{
7 Vid. Fernández Rodríguez, Carmen. Documentación Administrativa (nº . 259-260 enero-agosto, 2001. Cit. Págs. 60-66.
} 
aliza mediante el denominado Plan Territorial Sectorial de Ordenación de los Recursos Turísticos, en el que se define muy genéricamente el modelo de desarrollo turístico de la Comunidad y se ordena el fenómeno con arreglo al modelo previsto en los instrumentos de ordenación territorial. El Plan establece áreas territoriales -municipio, parte de él o de varios municipios- o comarcas turísticas consideradas como Preferentes desde la perspectiva de la actuación y financiación pública, y ello lo es a los efectos de la planificación detallada del aprovechamiento adecuado de los recursos turísticos existentes en ella.

Para que una Comarca pueda ser declarada turística ha de disponer de recursos turísticos básicos suficientes. El Plan Estratégico Comarcal se elabora una vez declarada una comarca como turística y para cada una de ellas, señalándose en la Ley -art. 51.1- que éstos, no tienen la naturaleza de los Planes Especiales dictados según la legislación sobre el Régimen del Suelo y Ordenación Urbana. Finalmente, el Departamento competente de turismo ha de emitir siempre informe preceptivo previo a la ejecución de las actuaciones y proyectos previstos por estos últimos planes y, en ausencia de ellos, el informe se emite con igual carácter cuando se prevean actuaciones y proyectos que puedan perjudicar la oferta turística de la zona donde vayan a ejecutarse.

Murcia: No se refiere esta Comunidad a específicos Planes de Ordenación Turística, aunque se regula en la figura del Municipio turístico que en la elaboración y modificación de los instrumentos de planeamiento urbanístico correspondientes a estos municipios. Se exige para ello que sea oída la Consejería competente en materia de turismo -art. 51 de la Ley 11/1997, de 12 de diciembre, de Turismo de la Región de Murcia-.

Asimismo, la Administración regional puede proceder a la declaración temporal de "Área Turística Saturada", en los términos y con los efectos que reglamentariamente se determinen.

Galicia: El principal instrumento de ordenación turística en esta Comunidad es el denominado Plan de Ordenación Turística, que según la Ley 9/1997, de 21 de agosto, de Ordenación y Promoción del Turismo en Galicia, se ha de coordinar con los instrumentos de ordenación territorial previstos en esta Comunidad Autónoma. El Plan de ordenación turística define el modelo de desarrollo turístico y contiene toda una serie de directrices generales referidas a aspectos turísticos diversos. Junto a estos Planes también se prevén los denominados programas específicos de protección del entorno medioambiental y de los espacios físicos con vocación turística, con el fin de evitar la degradación o destrucción del medio natural, y potenciar, preservar, acomo- 
dar y garantizar el medio ambiente. También se prevé en la Ley, la elaboración de los denominados Programas para la Preservación u Restauración de las Zonas Culturales con Valor Histórico; Plan de Promoción del Turismo y otros Planes y proyectos sectoriales.

Valencia: Ley 3/1998, de 21 de mayo, de la Comunidad valenciana regula la figura del Municipio Turístico y la denominada figura de los "Espacios Turísticos" que son las áreas delimitadas de territorio cuyas estructuras y actividades turísticas gozan de tal homogeneidad que permiten la ejecución de una política turística común y uniforme para todo el área. La Agencia Valenciana de Turismo es la encargada de elaborar el Plan de Espacios Turísticos con objeto de articular una política turística eficaz que permita el desarrollo turístico continuado de todos estos espacios conforme a determinados objetivos y con unas directrices generales o particulares. En este caso, el Plan únicamente tiene carácter orientativo para las Administraciones Públicas que ejerzan competencia sobre las materias afectadas en sus respectivos ámbitos, y siempre ha de respetar la distribución competencial básica vigente -art. 39-, lo cual equivale a explicar la anulación de una posible preferencia de la norma especial turística.

Extremadura: La complejidad planificadora alcanza en esta Comunidad sus niveles máximos en la Ley 2/1997, de 20 de marzo, de Turismo de Extremadura, que se refiere a los siguientes instrumentos: Plan Turístico Regional, que define el modelo y la estrategia de desarrollo turístico, así como la ordenación y fomento de los recursos turísticos dentro del marco del Plan de Desarrollo Regional; Plan Turístico Comarcal, que integra las políticas y acciones turísticas sobre ámbitos comarcales de índole turística, en función de los recursos existentes; Planes de Acción Turística Integrada, que son los que señalan áreas o comarcas turísticas para ser consideradas preferentes desde la perspectiva de la actuación y financiación pública, exigiéndose determinados requisitos para que sean declaradas como tales determinadas áreas o comarcas. La declaración de un territorio como área turística de acción integrada se efectúa mediante acuerdo del Consejo de Gobierno a propuesta de la Consejería de Turismo; Planes Estratégicos de Acción Turística Integrada, que son los Planes de ordenación y fomento de los recursos turísticos de las áreas o comarcas declaradas como turísticamente de acción integrada; y finalmente, los Planes de subsectores turísticos, que son los encaminados al desarrollo, mantenimiento y mejor aprovechamiento del sector, considerándose de interés los siguientes sectores: naturaleza y deportivo; patrimonial y cultural; educativo y sociorecreativo; congresual y trabajo; termal; rural y agroturismo; gastronómico; artesanías, y cualesquiera otros que por su implantación merezcan este tratamiento. 
Madrid: Ley de Ordenación Turística de la Comunidad de Madrid -Ley 1/1999, de 12 de marzo, de Ordenación del Turismo de la Comunidad de Madrid- introduce como una actividad más de esta Comunidad Autónoma en materia turística la actividad planificadora, y prevé la existencia de un Plan Regional Integral -que define los criterios y objetivos generales relativos al sector turístico y sus instrumentos- y de los Planes Parciales que tienen objetivos más concretos y han de integrar programas de actuación y los medios necesarios para su desarrollo -art. 39-. De otro lado, el Gobierno de la Comunidad Autónoma de Madrid, mediante Decreto aprobado a propuesta de la Consejería competente en materia de turismo, y previo informe de la Consejería a la que corresponde la ordenación del territorio, el Ayuntamiento o Ayuntamientos afectados, puede declarar a determinadas zonas "Áreas Especiales" que pueden ser o bien "Áreas de preferente uso turístico" cuando requieran de una más intensa actividad ordenadora o promocional turística, o bien "Áreas turísticas saturadas" que son aquellas en las que hay un exceso de oferta, o que por razones medioambientales sea desaconsejable aumentar su capacidad turística -art. 40-.

Cantabria: La Ley de Cantabria de Ordenación Turística -Ley 5/1999, de 24 de marzo- dedica un capítulo titulado: "El espacio físico", a la ordenación del planeamiento turístico, con el fundamento del asentamiento físico de la actividad turística. A partir de unos requisitos mínimos de infraestructura, y la declaración del principio del respeto medioambiental, establece la Ley de Cantabria zonas de preferente uso turístico -áreas concretas, y determinadas localidades, términos municipales o comarcas, en donde se den o se vayan a producir excepcionales circunstancias turísticas que precisen una especial acción turística, tanto ordenadora como promotora -y zonas turísticas saturadas-áreas concretas donde por exceso de oferta, por patente desequilibrio entre oferta y demanda o por acondicionamientos ecológicos o medioambientales, no se permita el incremento del turismo en alguna de sus actividades.

También se refiere esta Ley al instrumento de la comarca y el municipio turístico. Simultáneamente se prevé la figura del Plan Integral de Aprovechamiento de los Recursos Turísticos que pueden ser ejecutados por el Gobierno de la Comunidad, o a través de otras entidades públicas o privadas.

La Rioja: La Ley 2/2001, de 31 de mayo, de Turismo de La Rioja, también contempla como instrumento de planificación del Turismo, el Plan General de Turismo de La Rioja. Así vemos como en su artículo 25 se establece que: "El Gobierno de la Comunidad Autónoma de La Rioja, a iniciativa de la Consejería competente en materia de turismo, en coordinación con las Entidades 
Locales afectadas y previa audiencia del Consejo de Turismo, deberá aprobar un Plan General de Turismo de La Rioja. Dicho Plan, no tendrá carácter normativo". Se enumera expresamente en la Ley, el contenido que necesariamente deberá contener el Plan.

Los Planes Parciales serán aprobados por el Consejero competente, y se determina además en el Ley, que los Planes de Turismo se desarrollarán a través de programas en los que se concretarán las actuaciones sobre temas o aspectos determinados.

Cataluña: La Ley 13/2002, de 21 de junio, de Turismo de Cataluña, contempla la figura del Plan General de Turismo en su Capitulo II, en concreto en sus artículos del 13 al 17, estableciéndose en ellos una regulación detallada sobre el Plan de Turismo de Cataluña. En primer lugar, la Ley catalana considera el Plan de Turismo como un Plan Territorial sectorial, al amparo de lo que establece la Ley de urbanismo, y ha de justificar expresamente su grado de adecuación a las directrices del Plan Territorial General de Cataluña, que tiene como objetivo básico la planificación turística de la Generalitat.

En cuanto al contenido, se establece un total de nueve puntos desde donde se determinan las principales necesidades, objetivos y prioridades que el Plan debe contener, además de contener también, cuales serán los Departamentos competentes en cuanto a la redacción y aprobación del Plan. Como es obvio, el Plan tiene como ámbito de aplicación todo el territorio de Cataluña, y el desarrollo del mismo ha de ajustarse a los ámbitos de aplicación de los Planes Territoriales parciales establecidos por la normativa sobre política territorial. La vigencia del Plan de Turismo de Cataluña, en contraposición a otros Planes autonómicos es indefinida, sin perjuicio de que pueda ser objeto de modificación o revisión si las circunstancias lo aconsejan o si se modifican las directrices formuladas por el Plan Territorial General de Cataluña.

Sobre la actualización, el Departamento competente en materia de turismo, en colaboración y en coordinación con las Administraciones turísticas de carácter local, ha de actualizar, mediante la correspondiente Dirección General, y en la forma que se determine por reglamento, los estudios y los datos contenidos en el Plan de Turismo de Cataluña.

Navarra: La Ley Foral 7/2003, de 14 de febrero, de Turismo, hace referencia a la ordenación de los recursos turísticos en el Título V. A tal fin, la Ley de Navarra se expresa diciendo en su artículo 36, que "para ello la Administración turística elaborará un Plan de Ordenación de los recursos turísticos, 
que determine los objetivos, necesidades y prioridades, prestando especial atención a la mejora de la calidad de vida de los ciudadanos, y la conservación y protección del medio ambiente y del Patrimonio cultural.

La Ley establece además que la Administración de la Comunidad Foral, en colaboración con otras Administraciones y entidades públicas y privadas, elaborará los estudios, estadísticas, inventarios, y otros medios que sean precisos. En los artículos siguientes se determinan los principios que deben inspirar la política turística de la Comunidad Foral, distinguiendo entre la ordenación de los recursos turísticos naturales y culturales, así como la posibilidad de declarar determinadas áreas como saturadas o de especial densidad, ordenando las actividades turísticas a desarrollar en dichas zonas.

En resumen, esta Ley parece tratar de diversificar la oferta y adaptarla a los nuevos gustos de los usuarios.

Aragón: La Ley 6/2003, de 27 de febrero, del Turismo de Aragón, en su Título Segundo de "Ordenación Territorial de los Recursos Turísticos", habla de las directrices a seguir en cuanto a los recursos turísticos. Así en primer lugar, la ordenación territorial de estos recursos se realizará a través de las directrices parciales sectoriales de ordenación de los mismos, que observarán lo establecido en la legislación de ordenación territorial, y en todo caso, deberán respetar las Directrices Generales de Ordenación del Territorio de Aragón. Con carácter previo a la elaboración de las Directrices Parciales Sectoriales de Ordenación de los Recursos Turísticos, el Departamento del Gobierno de Aragón responsable de turismo formará un inventario de los recursos turísticos existentes en el territorio aragonés.

Las Directrices Parciales Sectoriales de Ordenación de los Recursos Turísticos contendrán las siguientes prescripciones: Definición del modelo de desarrollo turístico de la Comunidad Autónoma; Determinación de las necesidades, objetivos, prioridades y programas de actuación; Modos óptimos de aprovechamiento y protección de los recursos turísticos, con especial atención a los aspectos de preservación y restauración de los valores ambientales y culturales; Adecuación del planeamiento urbanístico, y en su caso, a las propias Directrices, y Previsiones relativas a cualquier otro aspecto condicionante del desarrollo de las actividades turísticas.

\subsection{Peculiaridades del hecho insular.}

La incidencia de la ordenación del territorio sobre le turismo es mucho mayor en las Islas que en el entorno peninsular ya que no podemos olvidar la 
limitación propia de los territorios insulares. Así, las normativas Autonómicas de Canarias y Baleares parecen introducir mayores medidas de limitación, o estándares de actuación que puedan por tanto limitar una eventual planificación futura. En estas zonas insulares se empieza a tomar conciencia al respecto en la década de los ochenta, a través de las distintas normativas autonómicas. Ya en los noventa, se observan cambios en las estrategias en estos destinos turísticos tradicionalmente de sol y playa, así como también se observan cambios en el análisis de las normativas en la ordenación de los territorios insulares.

\subsection{A) Baleares}

Fue a mediados de los años ochenta, cuando en las Islas Baleares se tomaron las primeras medidas autonómicas de ordenación de los establecimientos y alojamientos turísticos. Con la intención de regular esta situación, el Gobierno Balear aprobó el Decreto 30/1984, de 10 de mayo, de medidas de ordenación de establecimientos hoteleros y alojamientos turísticos. Muchos son los autores que se han pronunciado, con respecto a la ordenación de la oferta turística de las Islas Baleares. El profesor Blasco Esteve aborda el problema de la planificación del territorio turístico en estas Islas centrándose en la contención de la densidad de población en las mismas, y analizando las limitaciones existentes en los Decretos Cladera I (Decreto 30/1984, en atención al nombre del entonces Conseller de Turismo), y Cladera II (Decreto 103/1987), este último, convertido luego en la Ley 7/1988, de 1 de junio, de Medidas Transitorias de Ordenación de Establecimientos Hoteleros y Alojamientos Turísticos, donde aparecen las primeras medidas de contención de la población turística al implantarse en ellos la llamada "Ratio Turística". Para Blasco Esteve, esta limitación del crecimiento espacial de las zonas turísticas no operaba aisladamente, sino que, además, dentro de ese suelo urbano y urbanizable "congelado", se limitaba también la densidad de población posible en el interior de los mismos ${ }^{8}$.

La ratio fue de 30 metros cuadrados por plaza en el Cladera I, siendo elevada a 60 metros cuadrados por plaza en el Cladera II, referida en todo caso, a nuevos alojamientos turísticos o a ampliación de los mismos ${ }^{9}$. La ratio turís-

\footnotetext{
${ }^{8}$ Vid: BLASCO ESTEVE, A. Ordenación y gestión del territorio turístico. Obra Conjunta, Director David Blanquer Criado. Ed. Tirant lo Blanch. Valencia, 2002. Cit. Págs. 215 y 216.

${ }^{9}$ El art. 3 de la Ley 7/1988 dice en concreto:

"Para construir de nueva planta un establecimiento hotelero o de alojamiento turístico, o para su ampliación, o para un cambio de uso de edificaciones con finalidad de utilización turística,
} 
tica opera desde su creación con una doble finalidad u objetivo: a) Por una parte, se trata de un requisito de calidad de los establecimientos hoteleros, ya que introduce un nuevo condicionamiento que tiende, por lo general, a reducir el número de plazas autorizables en una parcela determinada, mejorando así la confortabilidad de los clientes. Cabe pensar que a menor número de clientes en una misma superficie de terreno, mayor amplitud y mayor comodidad; b) Pero, por otra parte, la ratio turística es también un factor limitativo de la densidad poblacional en una determinada zona. ${ }^{10}$

Hasta la aparición de la ratio, en una parcela determinada en la que se quisiera construir un hotel se podían autorizar todas las plazas que cupieran en el edificio en cuestión -edificio cuyas características físicas eran determinadas por la normativa urbanística y no por la turística-, plazas cuyo número exacto se determinaba exclusivamente por aplicación de la legislación estatal sobre dimensiones de las habitaciones, es decir, por aplicación de una normativa que sólo atendía al interior de los hoteles. A partir de la ratio en cambio, se van a tener en cuenta no solo el parámetro citado (las dimensiones de las habitaciones, etc.), sino también este parámetro exterior que es la ratio turística, determinado en definitiva por la superficie del solar.

Unas determinadas normas del campo urbanístico vinieron a establecer instrumentos efectivos para que los topes de población establecidos en los Planes Urbanísticos no se desborden por la realidad y se cumplan efectivamente. Fueron exactamente los Decretos 27/1993 de 11 de marzo y 2/1996 de 16 de enero, sobre Regulación de Capacidad de Población. A estos efectos, los Decretos obligan a incorporar en los Planes (sea a través de revisiones de los mismos o por medio de normas complementarias de planeamiento) unos "índices de intensidad de uso", tanto residencial como turístico, que han de servir de base para calcular las capacidades de población resultantes del planeamiento.

será necesario una superficie en metros cuadrados de suelo edificable no inferior al resultado de multiplicar por 60 el máximo numero de plazas que pueda albergar el establecimiento.

Este suelo edificable quedará exclusivamente afectado por el uso turístico que se pretende y no podrá albergar otras instalaciones o construcciones que no estén estrictamente ligadas a la explotación turística que se solicita, según las normas que las ordenan.

La utilización del solar afectado distinta de la contemplada en el proyecto autorizado podrá dar lugar a la revocación de la utilización concedida..."

${ }^{10}$ Sobre este tema, puede verse in extenso SOCÍAS CAMACHO, J. M. La ordenación de las zonas turísticas litorales. Instituto Pascual Madoz. Universidad Carlos III de Madrid, 2001. Boletín Oficial del Estado. Cit. Págs. 231 y ss. 
Otra forma de limitación de la densidad poblacional la encontramos recogida en los Planes de Ordenación de la Oferta Turística (POOTs). Estos Planes realizan las limitaciones desde dos técnicas fundamentales:

El establecimiento de una densidad global máxima posible en los distintos tipos de suelo: los POOTs rebajan la densidad máxima a 60 habitantes/hectárea, por debajo de la cifra que hasta entonces se había manejado como óptima que era la de 100 habitantes/hectárea. Y el mantenimiento de la técnica de la ratio turística: finalmente los POOTs de 1995 de Mallorca, y de 1997 de Ibiza y Formentera, han mantenido con carácter general esta técnica, y el parámetro de ratio turística entre un mínimo de $60 \mathrm{~m}^{2} /$ plaza para la mayoría de las zonas turísticas en ellos delimitadas, y un máximo de 70 ó $75 \mathrm{~m}^{2}$ / plaza para alguna de ellas consideradas más saturadas. Pero esta última opción fue desechada finalmente por varios tipos de razones entre las que se encuentran: que de este modo no se mejoraba realmente el suelo ya consumido y las altas densidades existentes en el mismo, porque obligaba a destinar mucho suelo a los procesos de desarrollo urbanístico para poder obtener las parcelas resultantes de la aplicación de ratios altos, y porque ello podría suponer un encarecimiento del suelo turístico ${ }^{11}$.

La nueva política pública turística sobre el territorio en Baleares, se ha desarrollado a través de nuevas normas más restrictivas, de manera que, en la aplicación de estas, el crecimiento turístico sea más selectivo. El cambio de postura por parte de la Administración Autonómica competente sobre el planeamiento, se efectúa a través de una reacción contra aquellos Planes, reacción que se produce en la década de los noventa y que ha cristalizo en la desclasificación de extensas áreas de suelo previstos como urbanos o urbanizables. Es lo que el profesor Blasco Esteve considera "la congelación del suelo urbano y urbanizable existente" 12 .

La Ley de Ordenación Turística de Baleares 2/1999, de 24 de marzo, prevé como instrumentos de ordenación general de la oferta turística los denominados Planes de Ordenación de la Oferta Turística (POOT) y, en su caso, los Planes Territoriales Parciales (PTP). Dichos Planes no especifican su natu-

\footnotetext{
${ }^{11}$ Vid: BLASCO ESTEVE, A. Planificación y gestión del territorio turístico de las Islas Baleares. Ed. Tirant lo Blanch. Valencia, 2002. Cit. Pág. 247.

${ }^{12}$ Vid: BLASCO ESTEVE, A. Planificación y gestión del territorio turístico de las Islas Baleares. Ed. Tirant lo Blanch. Valencia, 2002. Cit. Pág. 231.
} 
raleza turística, no obstante establecen la densidad global máxima de población, delimitan zonas turísticas y de protección, y fijan su tamaño y características, estableciendo parámetros mínimos de superficie, volumetría, edificabilidad y equipamientos ${ }^{13}$. También pueden determinar estos parámetros respecto de las zonas residenciales colindantes con las turísticas -art.5-. Pero quizá la mayor novedad de esta Ley en relación a las del resto de Comunidades nos la ofrezca la previsión que la misma hace de planificación de la calidad turística a través del denominado Plan de Modernización Permanente ${ }^{14}$, cuya superación se impone a las empresas turísticas para poder seguir ejerciendo su actividad.

En este sentido es, significativa la Ley 6/1999, de 3 de abril, de Ordenación Territorial de las islas Baleares y Normas Tributarias, que de forma efectiva aprovecha el texto legal para condicionar tanto la planificación territorial como las subordinadas planificaciones sectoriales, entre las que se encuentra la ordenación turística. De hecho, la Ley introduce franjas de protección excluidas del proceso de urbanización (art. 19); limita el crecimiento del suelo urbanizable o apto para urbanizar en determinados porcentajes (art. 33); y sobre todo, subordina la planificación sectorial -puertos deportivos, equipamientos comerciales, residuos, oferta turística, carreteras, canteras, transportes, telecomunicaciones y energía- a los mandatos de esta Ley que, además, introduce una regulación mínima del contenido de algunos de ellos.

Consecuencia clara de esta vertebración entre las distintas planificaciones, es la reciente Ley 4/2000, de 22 de marzo, de moratoria de construcción y ampliación, de campos de golf en las Islas Pitiusas. En tanto no entre en vigor el Plan Territorial Parcial de Eivissa y Formentera, el legislador balear ha decidido paralizar la concesión de autorizaciones para construir o ampliar campos de golf como fórmula de reclamo de más afluencia turística.

\subsection{B) Canarias}

Con respecto a Canarias, debemos destacar que esta ha sido una de las Comunidades más sensibles a la consecución de la calidad del turismo, ya que

\footnotetext{
${ }^{13}$ Vid: SOCÍAS CAMACHO, J. M. La ordenación de las zonas turísticas litorales. Cit. Pág. 109.

14 No obstante, esta Comunidad ya venía aprobando diversos planes de modernización de la oferta turística complementaria -Ley 6/1996- y no complementaria para empresas y actividades turísticas concretas con anterioridad a su última Ley de Ordenación. Quizá la mayor novedad esté en el hecho de que esa exigencia sea permanente, dando lugar a una constante intervención administrativa a través de sucesivas autorizaciones -de tracto sucesivo.
} 
la Administración turística canaria ha sido consciente desde muy temprano de la importancia económica que el turismo supone en esta Autonomía.

La figura de los Planes Insulares de Ordenación del Territorio (PIOT) ${ }^{15}$ fue recogida en el Decreto $7 / 1995$ de 27 de enero $^{16}$, por el que se aprueba definitivamente el Plan Insular de Ordenación de la Isla de Gran Canaria. La regulación de este Decreto cuenta con un precedente legislativo importante, la Ley 1/1987, de 13 de marzo, reguladora de dichos Planes (que ha sido derogada por la nueva Ley 9/1999, de 13 de mayo, de Ordenación del Territorio de Canarias). Según expresa la exposición de motivos de la Ley 1/1987, se trata de llenar el vacío existente en cuanto a instrumentos supramunicipales de ordenación de la Isla de Gran Canaria, mediante la creación de una figura de planeamiento adecuado para la ordenación territorial, El Plan Insular.

Acerca del concreto contenido de los Planes Insulares podemos decir que se trata de instrumentos de ordenación del territorio urbanístico y de los recursos naturales que difieren del contenido exigido para los Planes Directores Territoriales de Coordinación por el artículo 11 del Reglamento de Planeamiento Urbanístico, pues a tenor del articulado de la Ley 1/1987, habían de contener, en más: La posibilidad de introducir indicativamente directrices de coordinación, o políticas territoriales en agricultura, pesca, industria y turismo; Medidas de protección del litoral; Interdicción de desarrollo urbano en las áreas no precisas para el crecimiento urbano; Clasificar y reclasificar suelo rústico; Posibilidad de suspender el otorgamiento de las licencias al momento de la aprobación inicial, y las determinaciones de los Planes de Ordenación de los Recursos Naturales.

El PIOT de Gran Canaria es una figura de ordenación territorial y urbanística que regula y ordena varios sectores bien diferentes: las zonas turísticas,

\footnotetext{
15 Vid: RODRÍGUEZ-ARANA MUÑOZ, J. La ordenación del territorio en las Comunidades Autónomas: los planes insulares canarios de ordenación. RDU, núm. 109 (1998); SANTANA AROZENA, F. y DOMÍNGUEZ VILA, A. y RUILOBA SANTANA, J. El nuevo ordenamiento jurídico-urbanístico canario. Ciudad y Territorio 77-3/1988. Cit. Págs. 103 a 110.

16 La Sala de lo Contencioso-Administrativo del Tribunal Superior de Justicia de Canarias (Sentencias de 8 y 9 de enero de 1998) ha declarado la nulidad del Decreto $7 / 1995$, por el que se aprobó definitivamente el Plan Insular de Ordenación de la Isla de Gran Canaria, por tres motivos fundamentales: invasión del ámbito propio de la autonomía municipal, vulneración de la reserva de Ley y producción en su tratamiento de irregularidades formales de grueso calibre (falta de información pública, entre otras). Esta Sentencia adolece de una escasa, por no decir inexistente, fundamentación.
} 
el suelo turístico, los espacios naturales, las actividades extractivas, el sector agrario, el patrimonio histórico, así como los sistemas de la infraestructura territorial (corredores costeros, carreteras, sistema aeropuertario y portuario, captación y distribución del agua, saneamiento y transporte de energía eléctrica). La zona turística litoral determinada por el PIOT fija un parámetro muy importante para los alojamientos turísticos, que denomina densidad, y que consiste en el establecimiento de una superficie mínima de suelo por cada plaza turística. No obstante, la fijación de este parámetro ha sido precisamente uno de los motivos de la anulación del Decreto 7/1995. En el Título II de las Normas Generales y Zonales del Plan Insular de Gran Canaria, se contiene el primer punto relevante en relación con la Ordenación de las Zonas Turísticas, estando destinado fundamentalmente a establecer con carácter vinculante las definiciones normativas de las categorías de alojamiento temporal o turístico y de residencia permanente, del producto turístico, y de oferta complementaria.

En segundo lugar, el PIOT también define el concepto de producto turístico. En relación al mismo, la Memoria del Plan Insular considera que la implantación del alojamiento turístico se puede asimilar al de los productos industriales, razón por la cual la implantación turística debe ofrecer algo más que simple alojamiento, como por ejemplo, otros servicios complementarios, instalaciones comunes, o buenas condiciones de entorno. Por otro lado, el artículo 26 de las Normas del PIOT prevé varias modalidades de productos turísticos: el hotel, el hotel especializado, el aparthotel, el mega-hotel, el "resort" (campos de golf, puertos deportivos), las casas de vacaciones, el apartamento y la villa. Todas estas modalidades tienen una característica común, como es que "urbanísticamente" deben contar con instalaciones y espacios comunes, es decir, con servicios y atributos complementarios al alojamiento que cualifican la oferta turística, y que, además, se deben dotar también del alojamiento necesario para hospedar a los visitantes en sus modalidades diferentes.

Por último, las normas del PIOT también definen el concepto de oferta complementaria o, mejor dicho, de equipamiento turístico. En la zonificación turística insular, la tarea más importante del Plan Insular de Gran Canaria en relación con la Ordenación de las Zonas Turísticas fue, sin embargo, la de delimitar precisamente esas Zonas, diferenciadas por completo de las que hubieran sido o pudieran ser destinadas a asentamientos de residencia permanente. En concreto, lo que se pretendía es que en estas Zonas Turísticas previamente delimitadas por el Plan, fuese de aplicación la regulación normativa establecida para los productos turísticos, de modo que finalmente, en las normas del PIOT se estableció que esas zonas son completamente diferentes de 
las de alojamiento permanente, y que además, se caracterizan por tener un uso exclusivamente turístico. El artículo 27 de las normas del Plan establece que es lo que se puede implantar en cada Zona turística. Así, en la Zona de la Costa Sur, se pueden desarrollar directamente productos turísticos con alojamiento temporal en suelo urbano y urbanizable ya calificado como de destino por el planeamiento municipal, o bien, por constituir áreas de potencial extensión de este uso. Pero además de lo anterior, el artículo 27.2 de las normas del PIOT señala tajantemente que el planeamiento municipal no puede destinar más suelo para alojamiento turístico fuera de las áreas en las que se permite el uso turístico por este Plan Insular. Es decir, que fuera de las dos Zonas turísticas delimitadas por el PIOT, no se puede destinar mas suelo a uso turístico. Esto significa que después de la entrada en vigor del PIOT, el planeamiento municipal debe calificar las zonas de uso turístico según las disposiciones del Plan Insular.

En cuanto a la densidad turística, las normas del PIOT se centran además en otro punto clave de la ordenación urbanístico-turística de las zonas litorales: la densidad, considerada esta como la determinación más importante para conseguir el "gran espacio del ocio en la Europa del año 2000". Tanto es así, que los redactores de la Memoria del PIOT entendieron que en el campo turístico el concepto de densidad cobra una dimensión y un carácter completamente distinto al del campo residencial, que debía reflejarse en el establecimiento de una densidad baja en las Zonas turísticas. La forma de fijar la densidad media en superficie por parte del Plan Insular de Gran Canaria, establece dos tipos instrumentales de densidad: Densidad Neta: Debía medirse sobre parcelas edificables respecto a una actuación determinada; Densidad Bruta: Por el contrario (art. 30 del Plan Insular de Ordenación Turística (PIOT) la densidad bruta debía medirse en ámbitos mayores a la parcela, en concreto, en ámbitos de programas de actuación urbanística (PAU) desarrollados por Planes municipales en las zonas turísticas de Gran Canaria. La comparación de los valores de la densidad neta recogidos en la norma de PIOT, con respecto a los Planes de Ordenación de la Oferta Turística de Mallorca y de Ibiza y Formentera tiene como resultado que el PIOT de Gran Canaria se queda muy corto si se comparaba con los referidos Planes de la Ordenación de la Oferta turística ya que el único parámetro urbanístico-turístico que efectivamente regula el PIOT, es la densidad neta de las Zonas Turísticas (que era el equivalente de lo que se ha dado en llamar ratio turística por la legislación balear).

En su Ley General Turística, Ley 7/1995, de 6 de abril, de Ordenación del Turismo de Canarias, esta Comunidad acoge, de un lado, los denominados Planes Regionales de Infraestructuras y el Plan Sectorial en Materia Turística 
-art. 10- y, de otro, a los denominados Planes Insulares de Ordenación Territorial, que son Planes de naturaleza urbanística -arts. 57 y 58-. El Plan Regional se aprueba en coordinación con los Cabildos Insulares y los Municipios más representativos por su desarrollo turístico, y es un instrumento que ha de abordar las necesidades, prioridades e infraestructuras relacionadas con el turismo. En el Plan Sectorial de interés general en materia turística, se incardinan las actividades de las Administraciones públicas concurrentes, fijando los objetivos, los programas de actuación, y los medios necesarios. Se elabora por la Consejería competente y se concierta en el ámbito de las Conferencias Sectoriales. Una vez informado por el Consejo Regional de Turismo y aprobado por el Gobierno se remite al Parlamento para su examen.

Los Planes Insulares de Ordenación Territorial -respecto a los que la Administración turística competente emite informe preceptivo y los Ayuntamientos afectados audiencia e informe previo a la aprobación definitiva- deben contener previsiones y núcleos, capacidad máxima, zona de influencia y límites de la oferta alojativa. En todo caso, las licencias de cualquier tipo que hayan de concederse en las zonas a la que han de referirse los Planes Insulares, o en suelo cualificado como de uso turístico, se han de otorgar de conformidad con el planteamiento y con las previsiones de la Ley de Ordenación, pues de lo contrario se prevé la sanción de su nulidad. En estas zonas insulares se necesita de forma urgente un cambio en el modelo de turismo existente hasta el momento, hacia otro modelo selectivo que facilite una preservación el territorio y un desarrollo turístico sostenible. Este es el objetivo de la Ley de Ordenación del Territorio de Canarias, Ley 9/1999, de 13 de mayo, que culmina un periodo legislativo que se había iniciado poco después de la asunción por esta Comunidad Autónoma de sus competencias en materia de ordenación territorial y urbanística, en el que tuvieron especial relevancia las Disposiciones que tenian por objeto el reconocimiento de las características peculiares del territorio canario. La misma Ley citada señala explícitamente en su exposición de motivos que el territorio, entendido como recurso natural, definido por sus características de escasez, singularidad, no renovabilidad, e insularidad, constituye la base del desarrollo económico y social del archipiélago. Además, se especifica, que los Planes Especiales de Ordenación pueden tener por objeto "conservar y mejorar el medio natural y el paisaje natural y urbano", "proteger y conservar el patrimonio histórico canario" o "definir las actuaciones en los núcleos o zonas turísticas a rehabilitar".

Recientemente se han aprobado en esta Comunidad Autónoma nuevos instrumentos jurídicos de ordenación del turismo, y todo ello sobre la base del objetivo propuesto por el legislador de lograr un modelo de desarrollo más 
sostenible y duradero para el territorio insular, especialmente respetuoso con el medio ambiente y conservador de los recursos naturales, del patrimonio cultural y del territorio, pero también, socialmente más equilibrado y justo, y generador de riqueza económica. El Gobierno canario encuentra en las Directrices de Ordenación, la herramienta más adecuada en tanto que instrumento de planeamiento del mismo Gobierno, que integra la ordenación de los recursos naturales y del territorio tendéntes a garantizar el desarrollo sostenible de Canarias, conforme a lo establecido por el Texto Refundido de las Leyes de Ordenación del Territorio de Canarias y de Espacios Naturales, aprobado por Decreto Legislativo 1/2000, de 8 de mayo.

Como primer paso en la configuración de un modelo más duradero, el Gobierno canario acordó, mediante el Decreto 4/2001, de 12 de enero, la formulación conjunta de las Directrices de Ordenación General y las Directrices de Ordenación del Turismo de Canarias, al entender, que la definición de un marco territorial y de los recursos naturales para el archipiélago, no podían ser eficaces dada su evidente interacción si simultáneamente no se diseñaba el marco para la principal actividad económica. El procedimiento seguido se encuentra descrito en las memorias de ambos instrumentos de ordenación.

Una nueva norma para ordenar el territorio turístico en las Islas Canarias ha sido la Ley 6/2002, de 12 de junio, sobre medidas de ordenación territorial de la actividad turística en las islas de El Hierro, La Gomera y La Palma. Esta Ley confirma desde su exposición de motivos la relación de dependencia de la actividad turística con el territorio, en la que éste, no es sólo el soporte físico en el que aquélla se produce, sino que es también y fundamentalmente el marco referencial del valor básico que la justifica y que le dio origen. La Ley $6 / 2002$, va ha desarrollar un régimen especial a través de instrumentos sectoriales de ordenación territorial de la actividad turística en dichas islas.

La Ley 19/2003, de 14 de abril, por la que se aprueban las Directrices de Ordenación General y de las Directrices de Ordenación del Turismo de Canarias, viene a suponer un nuevo instrumento jurídico de ordenación del turismo en Canarias. El objeto de esta Ley es la aprobación de estas Directrices, tal como establece su único artículo. Para la consecución de los objetivos, habrán de arbitrarse medidas que faciliten el tránsito entre el actual y el futuro modelo, hasta la adaptación al nuevo marco de ordenación de los diferentes instrumentos de planeamiento, tal como preveía para los Planes Insulares de Ordenación, el apartado 3 del artículo 5 de la Ley 6/2001, de 23 de julio, de medidas urgentes en materia de ordenación del territorio y del turismo de Canarias. Los motivos de la aprobación de esta nueva Ley se basan fundamental- 
mente en que un sector tan vital y dinámico como el turístico no puede quedar condicionado a un lento y encadenado proceso de adaptaciones sucesivas. Por ello, la Disposición Adicional Primera de la misma Ley habilita la figura excepcional de los Planes Territoriales Especiales de Ordenación Turística Insular como un instrumento ágil, de contenido sucinto y procedimiento abreviado que formulan los Cabildos Insulares, y a los que se dota de carácter vinculante. La perseguida simplicidad y agilidad obliga a esta Ley a evitar la duplicidad de instrumentos sectoriales de ordenación del ámbito insular, que establecía la Ley 6/2002, de 12 de junio, para las islas de El Hierro, La Gomera y La Palma, ya que en base a esta Ley, en estas islas se dispone de instrumentos similares.

Para el reforzamiento de la eficacia de las Directrices de Ordenación General, se modifican determinadas Disposiciones del Texto Refundido de las Leyes de Ordenación del Territorio de Canarias y de Espacios Naturales de Canarias, además de resultar necesario establecer determinaciones que faciliten la capacidad de actuación y eficiencia del planeamiento, adaptado y dirigido hacia los objetivos de sostenibilidad.

\section{EL PLAN GENERAL SOBRE EL TURISMO EN ANDALUCÍA ${ }^{17}$}

Para entender en su justa medida la importancia que tiene en Andalucía la actuación administrativa sobre el sector turístico, basta con saber, que hasta 1996, el turismo no estuvo integrado en esta Comunidad Autónoma en una Consejería propia, lo que da a entender la escasa importancia que hasta ese momento se le daba a la industria turística en la Comunidad andaluza. Consecuencia inmediata de la creación de la Consejería de Turismo y Deporte es que en 1998, se crea la Mesa del Turismo como Órgano de concertación social, e integrado por empresarios turísticos, agentes económico-sociales y la Administración pública turística, cuya actividad básica esta directamente relacionada con el turismo ${ }^{18}$. El resultado más inmediato de la Mesa del Turismo

\footnotetext{
17 Junta de Andalucía, Consejería de Turismo y Deporte: Plan General de Turismo de Andalucía I, Sevilla 2001, 143 págs, Junta de Andalucía, Consejería de Turismo y Deporte: Plan General de Turismo de Andalucía II, Sevilla 2002, 55 págs.

${ }^{18}$ La concreta constitución de Mesa del Turismo es: seis representantes de la Consejería de Turismo y Deporte; seis representantes de la Confederación de Empresarios de Andalucía; tres representantes de Comisiones Obreras de Andalucía; y tres representantes de la Unión General de Trabajadores de Andalucía.
} 
fue el Acuerdo alcanzado entre la Consejería, empresarios y sindicatos, y que se califico como Primer Pacto Andaluz por el Turismo. El Pacto se fundamentó desde la Consejería en: "La necesidad de Andalucía de redefinir su política turística de cara a los retos que se plantean con la llegada del nuevo siglo $^{19}$. Estos retos se visualizan de diferentes maneras, aunque la mayor parte de estas manifestaciones giran en torno a dos líneas principales de trabajo: En primer lugar, el diseño y elaboración de un nuevo Plan de Turismo ${ }^{20}$, que con una visión a largo plazo y en coherencia con el nuevo marco de planificación del conjunto de la economía andaluza, proporcione los instrumentos necesarios para impulsar la adaptación competitiva del sector. Se propone para ello el establecimiento de un marco eficiente de coordinación en materia turística entre las Administraciones públicas, que posibilite una mejora en el cumplimiento de los objetivos que se propongan en el Plan ${ }^{21}$. En segundo lugar, la elaboración de una Ley del Turismo de Andalucía que implique la adaptación del marco normativo a las exigencias actuales del sector a su previsible evolución y a la necesidad de una progresiva armonización normativa con la Unión Europea”. Esta Ley a la que se hace referencia en el I Pacto Andaluz por el Turismo es la 12/1999, de 15 de diciembre, del Turismo de Andalucía.

El capítulo II del Titulo Tercero de la misma Ley del Turismo, que trata de la "Ordenación de los Recursos Turísticos", prevé la existencia del Plan General de Turismo en su artículo 15. Este Plan destaca por su vocación integral, y esta llamado a definir el modelo y la estrategia de desarrollo turístico de la Comunidad Autónoma, sin perjuicio de su eventual desarrollo con relación a sectores específicos a través de programas ejecutivos. Vemos como la ordena-

\footnotetext{
${ }^{19}$ Vid: I Pacto Andaluz por el Turismo. Consejería de Turismo y Deporte. Documento de Trabajo. Publicaciones Generales. Junta de Andalucía, Sevilla, 1998. Cit. Pág.7.

${ }^{20}$ La necesidad de un nuevo Plan de Turismo viene dada,por el agotamiento del anterior modelo de planificación turística, que tiene su reflejo en el Plan de Desarrollo Integral del Turismo en Andalucía (Plan DIA). Este Plan estaba configurado en los últimos años como referente adecuado e idóneo de la política turística en la Comunidad Autónoma. Según lo acordado en el Pacto por el Empleo y Desarrollo Económico de Andalucía, el diseño y elaboración de un nuevo Plan de Desarrollo Turístico de Andalucía deberá servir para sentar las bases de la actividad turística en la Comunidad Autónoma y analizar los retos y necesidades futuras del sector turístico en Andalucía.

${ }^{21}$ Fruto de este Acuerdo fue la creación en 1998 del Consejo Interdepartamental en Materia de Turismo. Vid: Pacto Andaluz por el Turismo. Junta de Andalucía. Consejería de Turismo y Deporte. Publicaciones Generales. Sevilla 23 de febrero de 1998. Cit. Pág. 2.
} 
ción de los recursos turísticos se hace a través del Plan, el cual determinará las principales necesidades, objetivos, prioridades, y programas de acción, y definirá el modelo y la estrategia de desarrollo turístico de la Comunidad Autónoma, así como, el fenómeno de los recursos turísticos de Andalucía. Los programas territoriales que están diseñados en la Ley del Turismo de Andalucía son:

"Zonas de Preferente Actuación Turística", para comarcas emergentes, e implica la elaboración de un "Plan de Actuación Turística Integrada" formalizado mediante convenio entre la Consejería de Turismo, las Entidades Locales interesadas así como, en su caso, otras Administraciones, asociaciones u organismo.

"Programa de Recalificación de Destinos", diseñado para destinos maduros con problemas de saturación, teniendo por objeto la mejora de la calidad y la recuperación ambiental.

"Programas de Turismos Específicos" que están pensados para potenciar subsectores turísticos determinados que puedan aportar especiales sinergias sobre el conjunto del sector.

Estos instrumentos de ordenación son coherentes con el hecho de que la actividad turística es una de las actividades económicas con mayor incidencia territorial en Andalucía. En ese sentido, el turismo juega un papel fundamental en la construcción del modelo territorial de la Comunidad, y su planificación debe hacerse en plena coherencia con la planificación territorial ya definida en las bases y estrategias del Plan de Ordenación del Territorio de Andalucía.

\section{PROCEDIMIENTO DE ELABORACIÓN DEL PLAN GENERAL DEL TURISMO}

La Orden de 26 de abril de 2001, de la Consejería de Turismo y Deporte, aprobó la primera formulación del Plan General del Turismo de Andalucía, en sintonía con el mandato estatutario (art. 12.3.3ํㅜ del Estatuto de Autonomía de Andalucía). El Documento de formulación del Plan ${ }^{22}$ tuvo como útil refe-

\footnotetext{
22 Vid: Plan General de Turismo de Andalucía I, Sevilla 2001, cit, pág. 3.
} 
rencia los planteamientos y resultados alcanzados por el Plan de Desarrollo Integral del Turismo en Andalucía (Plan DIA) ${ }^{23}$, pues, aunque las circunstancias en las que se definió el Plan DIA, así como su estrategia, son sustancialmente diferentes a las actuales, los planteamientos que se establecieron y los resultados que se alcanzaron durante su ejecución, han proporcionado un punto de apoyo para afrontar los trabajos de redacción del nuevo Plan General de Turismo. La Orden de 26 de abril de 2001 fue expresamente derogada por la disposición derogatoria única del Decreto 22/2002, de 29 de enero, de formulación del Plan General del Turismo de Andalucía.

La Disposición Adicional Quinta de la Ley 12/1999, del Turismo, establece que el Plan General de Turismo tendrá la consideración de un Plan con incidencia en la ordenación del territorio, siéndole de aplicación, por tanto, la Ley 1/1994, de 11 de enero, de Ordenación del Territorio de la Comunidad Autónoma de Andalucía, la cual dispone que la formulación de estos Planes corresponde al Consejo de Gobierno, a propuesta del Consejero competente sobre la materia sectorial. Se dispone también en el Decreto de 22/2002, de formulación del Plan, que el mismo será revisado con una periodicidad no superior a cuatro años. Según establece el artículo cuarto de dicho Decreto, el procedimiento de elaboración del Plan será el siguiente: "Elaborado por la Consejería de Turismo y Deporte el proyecto del Plan General del Turismo, este se someterá al Consejo de Coordinación Interdepartamental en materia de Turismo, siendo aprobado inicialmente por el titular de la Consejería de Turismo y Deporte, e informado por el Consejo Andaluz del Turismo, el Consejo Andaluz de Municipios y el Consejo Andaluz de Provincias, así como por la Consejería de Obras Públicas y Transportes, y remitido a la Comisión Europea y al Ministerio de Economía para su informe. A continuación, será sometido a información pública. Los Informes y las observaciones presentadas se valorarán por la Consejería de Turismo y Deporte, siendo aprobado provisionalmente el Plan General del Turismo por su titular. Realizada esta aprobación, se elevará al Consejo de Gobierno el cual lo remitirá al Parlamento de Andalucía para su conocimiento, y finalmente, será exami-

\footnotetext{
${ }^{23}$ La Comunidad Autónoma andaluza pone en marcha en 1993 el Plan de Desarrollo Integral del Turismo en Andalucía (Plan DIA), con el fin de afrontar la situación de recesión en que se encuentra el sector desde fínales de la década anterior. Se trata de impulsar una nueva etapa de crecimiento que permita aprovechar las posibilidades reales del sector, y su adaptación a los procesos de transformación que se están produciendo en ese momento en el mercado. Partiendo de la realización de un minucioso estudio de diagnóstico y de la definición de un escenario en el que situar la evolución del turismo andaluz, se propone un conjunto de actuaciones dirigidas a procurar un desarrollo armónico y cualificado del sector.
} 
nado por la Comisión Delegada de Planificación y Asuntos Económicos y aprobado por el Consejo de Gobierno, publicándose en el Boletín Oficial de la Junta de Andalucía”.

Este Plan fue remitido al Parlamento Andaluz por el Consejo de Gobierno de la Junta de Andalucía con fecha de 30 de septiembre de 2003, y posteriormente ha sido presentado por el Consejero de Turismo y Deporte ante la Comisión Delegada de Planificación y Asuntos Económicos, con fecha de 20 de noviembre de 2003, por lo que a la hora de redactar este trabajo esta a falta del trámite de aprobación por el Consejo de Gobierno y su publicación oficial.

\section{ESTRUCTURA Y CONTENIDO DEL PLAN GENERAL DEL TU- RISMO DE ANDALUCÍA}

El Documento del Plan General del Turismo de Andalucía ha sido elaborado por la Consejería de Turismo y Deporte, y consensuado por los agentes sociales representados en la Mesa del Turismo. En dicho Plan se determinan las necesidades, objetivos, prioridades y modelos de acción, y se define el modelo y la estrategia de desarrollo turístico de Andalucía y el fomento de sus recursos para los próximos tres años. En el se observan dos cuerpos o partes claramente diferenciados: uno referido al diagnóstico desde la oferta y la demanda, donde se contempla además un diagnóstico exhaustivo de la situación actual y perspectivas en el sector, y en el que se pone además de manifiesto su capacidad para generar una actividad económica inducida, y la posición de privilegio que Andalucía ocupa en los mercados nacional e internacional. Una segunda parte programatica, donde se recogen los fines y objetivos de la política general del turismo en Andalucía, así como una serie de estrategias desarrolladas a su vez por Medidas e Instrumentos para conseguir alcanzar el objetivo finalista del mismo, que no es otro que la consolidación del turismo como sector clave para el desarrollo futuro de Andalucía, así como, generar riqueza y empleo en la economía andaluza. En este sentido, el enunciado del Plan incide en la necesidad de que al Turismo le corresponda el máximo nivel de protagonismo en la estrategia global de desarrollo de Andalucía, debido, fundamentalmente, a: el peso que tiene esta actividad dentro del conjunto de la economía andaluza; a su contrastada capacidad de generación de efectos de arrastre y, consiguientemente, de generación de actividad y empleo inducido; y a las expectativas de crecimiento de futuro de la actividad debido a la posición de privilegio que Andalucía ocupa en el mercado nacional e internacional. 


\subsection{Primera parte del Documento del Plan.}

Los objetivos generales del Plan General del Turismo con respecto a este primer cuerpo del documento del Plan se encuentran en la realización de un análisis exhaustivo de la situación y perspectivas del sector con respecto a su capacidad para generar una actividad económica, y la posición de privilegio que Andalucía ocupa en los mercados turísticos. Dentro de este primer cuerpo del Plan, y con respecto a la oferta y la demanda, los objetivos a conseguir son ${ }^{24}$ :

\subsection{A. Realizar análisis de la evolución y de la actual situación del turismo en Andalucía}

Para ello, en el documento del Plan General del Turismo se empieza hablando de la situación de partida del turismo en Andalucía, primeros años de la década de los noventa, encaminándose hacia un cambio de modelo y exponiendo la situación del turismo español en esta época, que como sabemos, estuvo condicionada y afectada por la generalización de las crisis económica internacional, y por los problemas de inseguridad que se derivaron de los conflictos en el Golfo Pérsico así como de la inestabilidad política en la región magrebí. Se realiza también un análisis desde el marco económico e institucional y dentro del contexto internacional, nacional y andaluz.

En el marco económico se exponen las previsiones económicas de los diferentes organismos internacionales y nacionales referidos al sector turístico, haciendo hincapié en que el fuerte crecimiento de la demanda interna debido a la estabilidad económica de la segunda mitad de la década de los noventa, junto con la espectacular subida de los precios del crudo y la fuerte depreciación experimentada por el euro en el año 2000, podrían llevar a una inflexión en el ciclo económico. En el marco institucional se parte del contexto europeo desde el proceso que se pone en marcha en Europa con la firma del Tratado de la Unión en febrero de 1992, y que va a suponer un cambio transcendental con respecto a anteriores planteamientos. En el marco institucional español, el documento determina que: "Las políticas de fomento y ordenación turística son competencias transferidas a las Comunidades Autónomas. Ello significa, que en principio, son estas últimas las que tienen en sus manos las herramientas necesarias para definir las condiciones de competitividad de su

\footnotetext{
${ }^{24}$ Dada la amplitud con la que han sido tratados cada uno de estos puntos en el Documento de formulación del citado Plan, nos remitiremos brevemente a lo establecido en él para cada uno de ellos. Véase Plan General del Turismo de Andalucía I. Cit. Págs. 3-143.
} 
aparato productivo, pero siempre de conformidad con las directrices generales que para el funcionamiento a corto plazo establezcan las políticas de estabilización o coyunturales, y las políticas estructurales que sean competencia de la Unión Europea.". En el marco institucional andaluz se establece que "será el Plan Económico Andalucía siglo XXI, el que debe establecer cuales son las directrices de la política de la Junta de Andalucía en el inicio del nuevo siglo". Considerando como el documento de planificación económica más actualizado el Plan de Desarrollo Regional de Andalucía 2000-2006, se pone de manifiesto que: "El incremento de la generación de valor del sistema socio-económico para asegurar un desarrollo sostenible se convierte en el principal objetivo que contribuye a mejorar la posición de Andalucía en el marco europeo”.

\subsection{B. El Turismo en la economía andaluza}

Según las indicaciones de este Plan: "La economía andaluza inicia en 1994 un proceso de fuerte crecimiento y estabilidad propiciado por la generalización de la recuperación económica en España y en Europa (que explica el protagonismo que en los impulsos iniciales asumen los ingresos por exportaciones y turismo), por la progresiva implantación de reformas estructurales. En los últimos años de la década de los noventa, la economía andaluza ha crecido por encima de la media española, con una tasa anual acumulativa próxima al $4 \%$, aunque esto no significa que hayan desaparecido los problemas estructurales que tradicionalmente le han caracterizado" 25 .

\subsection{Análisis de la demanda del turismo y sus tendencias. Análisis de la oferta.}

Para el análisis de la demanda se determinan en primer lugar las grandes tendencias del turismo realizando un estudio del comportamiento de la misma incluyendo en ello un análisis prospectivo y cualitativo de esta. Se dice en este punto que: "Si algo caracteriza en este momento al turismo es la intensidad y rapidez de los cambios que está sufriendo como actividad organizada y como producto de consumo, y así vemos como se pueden distinguir unas ten-

\footnotetext{
${ }^{25}$ Actualmente la realidad del turismo en Andalucía se pone de manifiesto a través de los datos macroeconómicos consolidados y recogidos en el Balance del Año Turístico de Andalucía del año 2002. Así, el número de turistas que visitaron la Comunidad durante el citado año, fue de 21.000.000. Durante el mismo año 2002, se estima que se alcanzan 37.000 millones de euros. Para satisfacer los bienes y servicios requeridos por los turistas que han visitado Andalucía a lo largo del año 2002, la economía andaluza en su conjunto habrá tenido que producir por valor de 11.904 millones de euros, aportando el 14\% al PIB andaluz.
} 
dencias envolventes que están por encima del turismo y que afectan a la economía en su conjunto, y otras tendencias dentro del cambio que se centran, junto con las propias modificaciones impulsadas desde el lado de la oferta, en los cambios de las preferencias y actitudes que transforman los modelos de consumo turístico":

\section{a) Las tendencias envolventes}

Entre las tendencias envolventes con influencia directa sobre el turismo se distinguen las tendencias económicas, las políticas, las culturales y las demográficas. Las tendencias económicas son las que se consideran más significativas y tienen una repercusión inmediata. Las dos más importantes e íntimamente relacionadas entre sí, son el crecimiento económico sostenido y la mayor globalización e integración de la economía mundial en los países desarrollados. A las tendencias políticas se las considera menos evidentes y cuantificables, dada la alta fragilidad de esta variable, pero no por ello, carecen de importancia. De indudable trascendencia para el turismo es la existencia de zonas localizadas de conflicto que están, en mayor o menor grado, vetadas para el turismo (Argelia, Irak, Los Balcanes, algunos países africanos). Desde el punto de vista cultural, conviene señalar como tendencia envolvente el aumento de la formación y de la información del ciudadano. Esto tiene su reflejo directo en las actitudes que el turista adopta sobre su tiempo libre y en los modelos de consumo turístico. De aquí nace la exigencia de una mayor calidad y cualificación del producto y del destino turístico por parte de los demandantes. Las tendencias demográficas son mucho más concretas y cualificables. En primer lugar, el envejecimiento de la población europea (el principal cliente para Andalucía), que supone la necesidad de recualificación de la oferta en su conjunto (accesibilidad, atención médica, etc.). En segundo lugar, el notable incremento de los viajes de jóvenes, de mujeres independientes y de parejas jóvenes.

\section{b) Las tendencias internas}

Dentro de las tendencias internas, se distingue entre las que se pueden considerar como características estructurales del sector (donde sólo pueden apreciarse cambios relativos), y las tendencias de la demanda, que son las que han experimentado una mayor transformación en los últimos años. Las tendencias estructurales se encuentran relacionadas con la tendencia a la globalización e integración y con el propio proceso de expansión y de maduración del sector turístico como tal, y así se habla de un crecimiento turístico desacelerado, y de un turismo regional pero en proceso de interregionalización y 
con un alto grado de concentración turística con tendencia a la dispersión. En cuanto a los cambios en las tipologías de la demanda se consideran los que mayor influencia pueden tener en Andalucía a corto plazo ya que se están produciendo de manera acelerada y dando lugar a nuevas formas y modelos de consumo.

De esta forma se contempla la "aparición de nuevos turistas"; y "cambios en las motivaciones”, que son los más importantes y generalizados, pudiendo agruparse básicamente en dos: la diversificación motivacional y la creciente sensibilidad del turista hacia los aspectos medio-ambientales y culturales. Por último, "cambios en el modo de consumo", que afectan directamente a la relación entre el consumidor y el productor de servicios y productos turísticos. $\mathrm{Su}$ origen se halla en las referidas tendencias envolventes culturales, aunque también se ven influenciados por las de carácter económico, especialmente por la consolidación y maduración del turismo como sector. En este grupo, el Plan distingue tres tendencias: mayor exigencia de calidad; personalización del viaje, y posicionamiento activo de los turistas. A los efectos del documento del Plan; "Si algo caracteriza al turismo en este momento es la intensidad y rapidez de los cambios que está sufriendo como actividad organizada y como producto de consumo. Esta es la tendencia más importante a tener en cuenta, ya que relativiza todas las demás. Admitiendo por evidente esta "tendencia al cambio" se pueden distinguir unas "tendencias envolventes", que están por encima del turismo y que afectan a la economía en su conjunto, y otras "tendencias dentro del cambio" que se centran, junto con las propias modificaciones impulsadas desde el lado de la oferta, en los cambios en las preferencias y actitudes que transforman los modelos de consumo turístico". ${ }^{26}$

\section{c) Mercados emisores y receptores}

En el Plan General del Turismo se concretan desde el punto de vista geográfico cuales son los principales cambios y tendencias en los hábitos de los turistas distinguiendo por países y destinos:

\section{Mercados emisores reales y potenciales}

Los cambios en la actividad turística no vienen dados sólo por las motivaciones del turista y por las modalidades de turismo, sino que también se producen por la aparición de nuevas oportunidades de mercado en zonas dife-

\footnotetext{
${ }^{26}$ Vid: Plan General del Turismo de Andalucía. Junta de Andalucía II, cit. pág. 35.
} 
rentes a las tradicionales. Uno de los factores actualmente más relevantes lo constituye la entrada en el mercado de zonas emisoras emergentes, ya sea por el volumen de turistas, o por las características de las mismas. Se determina que "un buen conocimiento de los mercados emisores permite a un destino seleccionar aquellos que considere más interesantes para cumplir los objetivos que se haya propuesto." Los mercados de mayor tradición turística estarían constituidos por un primer grupo entre los que se encuentran Norteamérica, Japón y algunos países de Europa Occidental. El segundo grupo suele denominarse "nuevos mercados" y en este se incluyen algunos países de la Europa del Este y los asiáticos Malasia, Taiwan y China. A pesar de la aparente homogeneidad de estos grupos, dentro de ellos se pueden apreciar realidades diferentes. Entre los emisores tradicionales, E.E.U.U., Reino Unido y Japón, presentan una situación de fortaleza; Alemania y Francia sólo mantienen sus cuotas; y Canadá e Italia, pasan por una acentuada crisis de la que parecen estar saliendo en la actualidad. Las previsiones para el período 2000-2010 son diferentes en los cinco primeros países emisores, siendo Japón el único que mantendrá tasas de crecimiento superiores a la media. Teniendo en cuenta la situación de Andalucía, Europa sigue siendo el mercado emisor de mayor interés, sobre todo Alemania, Reino Unido y Francia, países sobre los que se presenta una importante ventaja estratégica. Fuera del continente destacan (por sus cifras de salidas totales, de gasto y hábitos de consumo a lo largo del año) Estados Unidos y Canadá, aunque la

distancia y el escaso interés de los norteamericanos por salir de su país, les convierte en un mercado difícil.

\section{Mercados receptores: Estudio de la competencia}

Con respecto a este punto, el Documento de formulación del Plan comienza diciendo que: "Es evidente que la competencia entre destinos es algo bastante complejo, donde intervienen factores de la más diversa índole como las infraestucturas de servicios públicos, el orden social, los precios, el clima y, por supuesto, las instalaciones y los productos turísticos". Para el Plan General, las estrategias a desarrollar ante los competidores deben ser distintas, tanto en sus objetivos como en sus vías de actuación según se consideren cada una de las cuatro posibilidades de competencia. Lo realmente importante será identificar claramente quienes son esos competidores, qué importancia relativa tiene cada uno de ellos, qué perspectiva de futuro y cuáles son sus ventajas y desventajas comparativas respecto a Andalucía. Es evidente que un análisis de este tipo no debe considerar solamente la situación actual, sino que ha de proyectarse hacia el futuro y evaluar también lo que se denomina competencia potencial. $\mathrm{Al}$ respecto, se habla de: Competidores nacionales: Es un primer ni- 
vel de competencia de gran importancia para el turismo andaluz si se tiene en cuenta el peso real y potencial del turismo interno en la Comunidad Autónoma de Andalucía, y las elevadas cuotas de mercado de los países emisores en otros destinos españoles, como los alemanes y los británicos en las zonas insulares, y los franceses en Cataluña y la zona levantina. En el mercado español, los principales competidores internos son las Baleares y toda la Costa mediterránea, a los que hay que añadir, en la época invernal, la ciudad de Madrid y la región de Castilla-León. En este nivel deben aprovecharse ventajas como la cercanía, el clima o las diferentes tipologías de productos y destinos como elementos atractivos para la demanda. El Mediterráneo. La competencia de producto: El segundo bloque competidor está formado por los principales destinos situados en torno al Mediterráneo, que alberga los que han sido tradicionalmente el principal mercado turístico europeo. En este conjunto de países cabe diferenciar los del sur de Europa de los de Oriente Medio y el Norte de África. El viejo continente. La competencia de la industria: Se dice que en este caso, la competencia no proviene sólo de destinos similares, sino también de otros capaces de cubrir con ofertas diferentes la misma demanda. En este sentido, la principal competencia de Andalucía se encuentra en la franja central del continente europeo, desde el Reino Unido a los países del Este; Competidores potenciales: Se parte de la idea de que existen numerosos destinos que a medio y largo plazo pueden llegar a convertirse en fuertes competidores para la Comunidad Autónoma andaluza, principalmente dentro del segmento de sol y playa. Ya han dado muestras de su potencialidad zonas como el Caribe, Oriente Medio, el Norte de África, e incluso los principales destinos de Asia Oriental y el Pacífico. El abaratamiento del transporte aéreo y la competitividad de los precios en estos destinos puede hacer que siempre que otros factores como la estabilidad política le sean favorables, lleguen a captar una cuota muy importante de los viajes europeos.

\section{d) Evolución y situación actual del turismo en Andalucía}

$\mathrm{Al}$ respecto, el Plan General del Turismo expone que: "El turismo andaluz ha mostrado una tendencia positiva en la dos últimas décadas, con un importante ritmo de crecimiento, especialmente entre 1994 y 1998, experimentándose en 1999 una menor tasa de crecimiento. La evolución económica internacional ha estado marcada en los últimos años por la inestabilidad financiera, lo que ha afectado a las previsiones de crecimiento de la economía mundial. La situación de ralentización de las tasas de crecimiento y la revisión de las expectativas futuras pueden significar un punto de giro del ciclo actual, que indudablemente afectará de manera negativa a la evolución del turis- 
$\mathrm{mo}^{27}$. La Organización Mundial de Turismo prevé un aumento de las llegadas de turistas con una tasa anual acumulativa del 3,4\%, lo que situaría el volumen mundial de llegadas en 1.018 millones en 2010 (frente a los 561 de 1995 o los 664 de 1999). La nueva situación económica ha obligado a dicha organización a modificar sus previsiones en cuanto a la distribución de los turistas entre las principales regiones mundiales. La O.M.T. considera que esta situación no afectará mucho a Europa, estableciendo a largo plazo, que los viajes desde el Viejo Continente se duplicarán entre los años 1993 (350 millones) y 2020 (728)."

\section{La demanda turística:}

Para el análisis de la evolución de la demanda turística se han utilizado en el Plan General del Turismo los datos que proporciona la Encuesta de Movimiento de viajeros en establecimientos hoteleros, que con periodicidad mensual elabora el Instituto Nacional de Estadística. Así se dice: "La demanda turística en Andalucía ha mostrado una tendencia creciente en las dos últimas décadas de modo que si en 1993 se produce una importante caída de la demanda turística nacional, en este año, la demanda extranjera comienza a recuperarse amortiguando con ello la caída de la demanda turística total. La evolución positiva del movimiento hotelero en la segunda mitad de los noventa ha supuesto una mejora en la posición de Andalucía como destino turístico en el mercado hotelero nacional. Por otra parte, el turismo extranjero con destino a Andalucía, ha estado siempre sujeto a una mayor variabilidad que el español." Con respecto a las principales características de la demanda turística, se analizan los diferentes aspectos que caracterizan la demanda de turistas con destino en la Comunidad Autónoma andaluza atendiendo al origen. Los turistas nacionales suponen el 54,4\% del total de los que visitan Andalucía. De ellos, el $57,2 \%$ proceden de otras regiones españolas y el 42,8\% son residentes en Andalucía que se desplazan por dentro de la Comunidad Autónoma, que en el caso del turismo extranjero, se observa un predominio absoluto de los países europeos, especialmente de los principales emisores de turismo (Alemania, Francia y Reino Unido), que concentran el 59,1\% del tu-

\footnotetext{
27 Según los informes del Instituto Nacional de Estadística, en 1999 se estimó que el turismo aportó a la economía española el 12,1\% y en sólo tres años, es decir, en el 2002, esta aportación se ha incrementado en un 3\%, siendo en la actualidad del 15,1\%. Además durante el período de tiempo comprendido entre 1996-2002, los ingresos estimados por turismo han crecido un 44\%, por tanto lógico desde estos resultados, el que las distintas Administraciones Públicas encuentren en el turismo un importante instrumento del desarrollo.
} 
rismo con origen fuera de España. En este grupo de países destaca la importancia del turismo británico $(36,7 \%)$ frente al alemán $(17,3 \%)$. Otro hecho destacable es el volumen de turistas europeos procedentes de otros países de la Unión Europea, que suponen el 24,4\% del turismo extranjero. Dentro de este apartado se distingue entre el turismo interno en Andalucía y el turismo del resto de España en Andalucía. En cuanto al primer punto, y en relación a la estacionalidad, predominan los viajes realizados en el período estival $(36,93 \%)$, seguidos por los del segundo trimestre $(22,62 \%)$ y los del cuarto $(22,34 \%)$.

En relación al medio de transporte, el automóvil (89\%) es el medio más utilizado por los turistas andaluces para sus desplazamientos. Le sigue el autocar, usado por un 6,6\%. En la distribución territorial, Málaga es la provincia que concentra el mayor porcentaje de la demanda turística de los andaluces, seguida de Cádiz y Granada. En relación al tipo de alojamiento, el más utilizado por los turistas andaluces ha sido el apartamento, la casa y el chalé, destacando dentro de este grupo la vivienda en propiedad (24,1\%). El alojamiento hotelero ha sido escogido por uno de cada tres andaluces que viajó por la Comunidad Autónoma. En relación al turismo del resto de España en Andalucía, se estima que supone el 31,21\% del total de llegadas a la región y el $57,26 \%$ del total nacional. Con respecto al turismo extranjero en Andalucía, se dice que los extranjeros significaron el $45,5 \%$ del total de turistas que acudieron a Andalucía. La mayor parte de ellos proceden de la unión Europea (el $83 \%$ del total de extranjeros), principalmente del Reino Unido $(36,7 \%)$ y de Alemania (17,3\%), encontrándose Francia más alejada (5\%). Se realiza también una descripción sistemática en cuanto a la estacionalidad, el medio de transporte, la distribución territorial, el tipo de alojamiento, la estancia media, el gasto medio diario, la organización del viaje, el motivo del viaje y la valoración de la estancia ${ }^{28 .}$

\section{e) Análisis de la oferta turística}

En el Documento del Plan General del Turismo, el estudio de la oferta comienza por el análisis de su evolución y continúa posteriormente con el examen de la situación actual y de las principales características de cada una de sus tipologías: alojamiento, restauración, agencias de viaje y oferta comple-

\footnotetext{
28 Véase: Documento del Plan General del Turismo de Andalucía. Decreto 22/2002, de 29 de enero. Cit. págs. 65-69.
} 
mentaria. El análisis se completa con una breve descripción del perfil empresarial medio de cada uno de los tipos de oferta. En el análisis global de los comportamientos empresariales de la oferta turística andaluza, se detectan conductas similares respecto a determinadas variables. Se trata de identificar dinámicas comunes entre los establecimientos turísticos andaluces atendiendo a su antigüedad, tipo de inversión, y grado de integración en estructuras superiores o nivel de formación. Ello permite hablar de diversos subgrupos de actividad que responden a sistemas de gestión y características parecidas, sin tener en cuenta si pertenecen o no a la misma actividad. Se realiza una descripción pormenorizada de cada una de las ofertas, y así tenemos como, dentro de la evolución de estas se detallan las tasas de crecimiento, la participación de las provincias en cada una de las ofertas, y las características principales de las mismas.

Mención especial merece dentro de la oferta, tanto los espacios turísticos genéricos como los específicos. Así vemos como el Plan dice: "Hoy es un hecho aceptado que los llamados turismos específicos son los que proporcionan mayor rentabilidad a las inversiones turísticas, los que otorgan más estabilidad en los mercados donde se asientan y los que cualifican los destinos en que se localizan. Para ello se dice que "se puede considerar que existe un turismo específico cuando algo es capaz de captar, por sí mismo, el interés de un número significativo de ciudadanos, logrando que ese grupo de personas se traslade al destino donde se encuentra para disfrutarlo, convirtiéndose, desde ese momento, en turistas. Es evidente que los turismos específicos dependen de las motivaciones de los turistas, y que estas pueden cambiar según las personas, los grupos y las épocas." 29

Dentro de los espacios turísticos genéricos, en el Plan General se destaca especialmente: Turismo de sol y playa: Es el de mayor entidad y el que provocó el "boom" turístico de Andalucía con un elevado impacto económico, social y medioambiental. Representa más de la mitad de la oferta turística andaluza y tiene plena implantación en los mercados nacional e internacional. La Costa del Sol es el destino más emblemático y consolidado de esta tipología, estando inmerso en una profunda transformación para aumentar su competencia en todos los mercados e introducirse en otros emergentes, mediante la renovación de sus infraestructuras e instalaciones, la creación de nuevos productos y el aumento generalizado de la calidad. Dentro de él se han desarrollado una

\footnotetext{
${ }^{29}$ Plan General del Turismo de Andalucía II, cit. pág. 92
} 
gran cantidad de turismos específicos y de actividades complementarias; $T u$ rismo de ciudad: Este turismo genérico es el más tradicional de todos y también suele llamarse turismo urbano o cultural. Dentro de él se incluyen el turismo artístico-monumental, el histórico y el de circuitos. Turismo rural: Se concreta en el Plan, que el interés por el turismo rural está íntimamente vinculado con la creciente importancia que entre las motivaciones del turista han adquirido los aspectos medioambientales, y los modos de vida y producción tradicionales. El potencial andaluz en este aspecto es considerable por los importantes valores paisajisticos y antropológicos que posee el medio rural. Además, el $17 \%$ de la superficie regional, está incluida en alguna figura de protección medioambiental, lo que supone una fuerte baza para el desarrollo del turismo ecológico. Entre los turismos específicos que mayor implantación tienen en Andalucía se destacan los siguientes:

Turismo de golf: El turismo de golf en Andalucía se puede considerar como un turismo específico consolidado con una demanda todavía creciente, siendo el más emblemático en cuanto a los beneficios sociales que estas tipologías pueden inducir. Se asegura en el Documento que un turista de golf gasta entre cinco y seis veces más que un turista de sol y playa. En la actualidad existen 70 campos de golf en Andalucía, de los que 37 se sitúan en la Costa del Sol. La mayor ventaja comparativa que tiene Andalucía para el desarrollo de este turismo es su clima, que permite la práctica de este deporte durante épocas del año en las que el centro y el norte de Europa es prácticamente imposible. Se asegura desde el documento que: "En contra de lo que puede parecer, no se trata de un subsector turístico empresarialmente "maduro", ya que pocos de los campos existentes están considerados de un modo integral como un negocio turístico".

Turismo náutico: El turismo náutico también se incluye en el grupo de los turismos deportivos, acogiendo dentro de él un amplio número de tipologías. Por su propia naturaleza, se localiza de forma casi absoluta en el turismo genérico de sol y playa. La mayor concentración se produce en la costa mediterránea, más desarrollada turísticamente.

Turismo de nieve: La estación de esquí de Sierra Nevada posee unas instalaciones e infraestructuras de alojamiento modernas y de alta calidad, contando además con el prestigio y la difusión que suponen haber organizado el Campeonato del Mundo de 1996. Ello la sitúa en una posición muy competitiva en un contexto de demanda en expansión en sus principales mercados, el regional y el nacional. Se considera que los problemas de estacionalidad inherentes a esta tipología han de ser planteados en el contexto concreto de ca- 
da destino, tratando de buscar otras actividades fuera de temporada que rentabilicen las infraestructuras turísticas existentes.

Turismo de reuniones: Con respecto a este tipo de turismo se dice en el Plan: "Aunque esta tipología se incluye normalmente en el turismo genérico de ciudad, puede caber en cualquiera de los otros dos, especialmente en los destinos de litoral, una de cuyas líneas de actuación para luchar contra la estacionalidad ha sido la construcción de infraestructuras (palacios de congresos, espacios polivalentes, salones de reuniones en hoteles) para la celebración de congresos, ferias y reuniones." Se trata de una tipología en expansión que incluye las modalidades de congresos, convenciones e incentivos. Es muy apreciada por los agentes sociales, y especialmente por las autoridades locales de los destinos, por su probada capacidad para generar riqueza, al presentar los turistas un gasto medio bastante elevado, buena parte del cual se destina a compras, restauración, y diversiones. Es por ello que se justifican muchas veces las grandes inversiones públicas para infraestructuras a pesar de la evidente falta de rentabilidad directa.

Turismo de aventura: Se encuadra dentro del turismo rural, siendo generalmente de carácter activo y al aire libre. Su demanda es cada vez mayor, estando vinculado en la mayoría de los casos a la juventud y al deporte. Presenta una gran variedad de posibilidades, siendo un turismo en continuo crecimiento. Se asegura que el nivel de gasto de estos turistas varía mucho según las tipologías. No se necesitan normalmente grandes instalaciones pero sí equipos caros y ubicaciones determinadas. El turismo de aventura comporta siempre cierto riesgo controlado.

Turismo de salud: Las vacaciones en balnearios que unen el cuidado de la salud y el descanso, cuentan con una gran tradición en Andalucía, habiendo vivido su edad de oro en la primera mitad del siglo XIX. Esa tradición balnearia ha ido debilitándose desde principios del siglo XX hasta hace una década, habiendo cerrado, o quedado reducidos a su mínima expresión, gran parte de los balnearios de la región. Al respecto, se hace hincapié en que: "En la actualidad, la ampliación del concepto de salud a la belleza y el mantenimiento corporal y psíquico, la vuelta hacia tratamientos más naturalistas (homeopatía) y el uso de estas instalaciones para los tratamientos geriátricos del IMSERSO como complementarios a la atención de la Seguridad Social, ha revitalizado esta tipología turística”.

Turismo gastronómico: Se considera que este suele situarse dentro del turismo rural y también como parte del turismo cultural y de ciudad, aunque en 
realidad cabe en cualquiera de los turismos genéricos existentes. Su desarrollo en Andalucía ha sido lento, no por una falta de tradición y recursos, sino por su alta correspondencia con las zonas de mayor renta, limitadas en la región hasta hace pocos años. En la actualidad conoce un momento álgido, con una elevada capacidad de crecimiento de cara al futuro.

Turismo ecuestre: "La progresiva consolidación de una nueva forma de entender el tiempo de ocio a partir de la realización de vacaciones activas está favoreciendo la aparición de diversas posibilidades para la satisfacción turística de un importante segmento de demanda. El turismo ecuestre es un buen ejemplo de ello, sobre todo por su estrecha vinculación con los destinos turísticos que están surgiendo en el espacio rural andaluz." 30

En el apartado de: Mercado de trabajo y recursos humanos, se dice: 'El mercado de trabajo en el sector turístico de la Comunidad Autónoma de Andalucía posee unas características propias a las que hay que atender para comprender su funcionamiento, localizar los problemas que presenta, analizarlos y buscar alternativas. En lo que respecta al análisis de la oferta de mano de obra, la población activa andaluza en el sector turístico ha crecido en los últimos años con una tasa inferior a la media nacional. Ello permite afirmar la existencia de una importante bolsa de mano de obra oculta, que explica que en el pasado, períodos de intensa creación de empleo, no hayan tenido un impacto proporcional en la disminución de las cifras de desempleados. Esta falta de relación entre el crecimiento del empleo y el crecimiento del sector se ha debido al aumento de la productividad de este último, propiciada por las economías de escala que se han ido produciendo con la concentración de empresas, y por la incorporación de las nuevas tecnologías en las mismas.

En la demanda, el Plan determina que la mano de obra ha ido evolucionando de acuerdo con las oscilaciones del ciclo económico. Así, desde el inicio de la crisis económica de principio de los 90, se produjo un proceso de destrucción de empleo. En estos momentos, se vive una coyuntura de creación de empleo, y puede afirmarse que la población ocupada en el sector turístico se encuentra en proceso de crecimiento. Muestra de ello es el incremento experimentado a partir de 1999, y que en ese año supuso ya el 12,8\%.

En cuanto a la formación, se percibe una mayor toma de conciencia de las necesidades reales del mercado de trabajo, manifestada principalmente en

\footnotetext{
${ }^{30}$ Plan General del Turismo de Andalucía I, cit. págs. 95-108.
} 
una reforma de la enseñanza reglada que aproxima considerablemente el aprendizaje al mundo real de las empresas".

\section{f) Territorio y sostenibilidad ${ }^{31}$}

Desde este apartado se analiza la incidencia medioambiental de los turismos específicos tales como turismo litoral (contaminación de las aguas; abastecimiento y distribución de las aguas; gestión de residuos sólidos; impactos sobre la conformación física del litoral); Turismo urbano (contaminación atmosférica y acústica); Turismo rural (impacto sobre Espacios Naturales Protegidos). El Plan comienza afirmando que el turismo es en esencia un consumidor nato de espacio: "Como es conocido, la actividad turística está siempre relacionada con el traslado y con la permanencia fuera de su residencia, lo que supone siempre una afección al territorio en tres sentidos diferentes." El desarrollo de los turismos específicos (turismo náutico, cinegético, de salud, de golf) ha puesto en uso nuevos espacios, de manera que cada vez se va ampliando más el territorio con vinculación turística.

La falta o la inadecuada ordenación de esos espacios, o la excesiva presión sobre los mismos, ha provocado en ocasiones el deterioro de los propios recursos que constituían la base motivacional, volviéndose en contra del propio proceso de desarrollo turístico. En segundo lugar, el turista ha de residir eventualmente en el lugar que visita, por lo que precisa de un espacio y un equipamiento para el alojamiento. Por último, el turista necesita de unas infraestructuras que permitan su desplazamiento y estancia en los destinos que elige, lo que supone también una transformación del territorio y el espacio-infraestructura, que también puede afectar a ciertos valores medioambientales (y por tanto, turísticos), si no se lleva a cabo una planificación adecuada.

El desarrollo del turismo en Andalucía en los años setenta y ochenta se ha dejado sentir sobre el territorio andaluz y particularmente sobre su litoral, que se ha visto ocupado (de forma intensiva en algunos casos), provocando deterioros del entorno que han intentado combatirse recientemente con políticas correctoras. En este sentido, el aspecto de mayor incidencia, por lo evidente de sus perjuicios hacia el contexto territorial, ha sido el urbanístico residencial. Para ello es imprescindible la colaboración de los Ayuntamientos, primera instancia planificadora y definitoria de los usos del suelo.

\footnotetext{
${ }^{31}$ Plan General del Turismo de Andalucía I, cit. págs. 119-143.
} 


\subsection{Segunda parte del Documento del Plan.}

En el segundo cuerpo del Documento de formulación del Plan, se establecen una serie de estrategias, desarrolladas a su vez por Medidas e Instrumentos con el fin de conseguir alcanzar el objetivo finalista del mismo, que no es otro, que la consolidación del turismo como sector clave para el desarrollo futuro de Andalucía, entendido como un sistema articulado de actividades con una importante capacidad para fomentar la sostenibilidad del medio ambiente y la identidad cultural de Andalucía, así como para generar riqueza y empleo en la economía andaluza ${ }^{32}$. Para cumplir con estos fines se ha dotado a dicho Plan con 573.650.000 euros que recogerán inversiones hasta el 2006 relativas a estrategias de desarrollo y fomento de los recursos turísticos, así como, un diagnóstico exhaustivo de la situación y perspectivas del sector en el que se pone de manifiesto su capacidad para generar una actividad económica inducida, y la posición de privilegio que Andalucía ocupa en los mercados nacional e internacional. Las estrategias fundamentales, en cuanto a su dotación económica, son:

\subsection{A) Promoción}

La principal partida corresponde al bloque de promoción, con 291,08 millones de euros. En este capítulo, la Consejería de Turismo y Deporte continuará su estrategia de considerar a Andalucía como destino turístico integral, prestando especial atención en sus campañas, al fomento de una única imagen de calidad que abarque la diversidad de productos y destinos turísticos. $\mathrm{Al}$ respecto, podemos subrayar un avance cualitativo y cuantitativo que es importante, aunque ya se sabe que nunca suficiente. Este Plan permitirá avanzar en estrategias de promoción para consolidar mercados que ya han dejado de ser emergentes para Andalucía, con lo que esta Comunidad Autónoma podrá seguir posicionandose en mercados que tendrán mucho que decir en los próximos años como puede ser el asiático.

\subsection{B) Ordenación de recursos}

Destacan también las inversiones previstas en las políticas de ordenación de recursos turísticos y reequilibrio territorial: 167,66 millones, que se pretenden emplear en programas relativos al turismo rural, grandes ciudades, se-

\footnotetext{
${ }^{32}$ Plan General del Turismo de Andalucía II, cit. Págs.1-55.
} 
ñalización turística, playas y comarcalización turística. También se abordará el desarrollo normativo de las figuras de las Zonas de Preferente Actuación Turística y de los Planes de Actuación Turística Integrada.

\subsection{C) Fortalecimiento del tejido empresarial y creación de empleo}

La tercera gran estrategia en cuanto a su dotación económica se traduce en medidas para contribuir al fortalecimiento del tejido empresarial y la creación de empleo, con un total de 47,94 millones. En este ámbito, el Plan pretende prestar especial atención y apoyo a las pequeñas y medianas empresa, a las iniciativas de asociacionismo empresarial y a los proyectos turísticos propiciados por mujeres y jóvenes.

\subsection{D) Dependencia estacional}

Junto con las tres estrategias anteriores que se consideran fundamentales por el Plan en cuanto a su partida presupuestaria, en la planificación que hace el Documento para los próximos tres años se afirma, que la ruptura de la estacionalidad que todavía presenta la actividad turística en Andalucía seguirá siendo un objetivo prioritario. Precisamente, a este concepto, se destinará un total de 9,013 millones de euros para crear nuevas rutas turísticas, fortalecer el papel de los palacios de ferias y congresos, incentivar las ofertas vinculadas a las demandas específicas, y apoyar a la organización de grandes eventos deportivos y culturales. Igualmente, el capítulo de ordenación y diversificación de la oferta, dotado con 4,7 millones de euros, se centrará en el desarrollo de la nueva normativa andaluza sobre hoteles, cámpings, apartamentos turísticos y viviendas vacacionales, al tiempo que se prevé la creación de una línea específica de ayudas para el fomento de la gastronomía andaluza.

\subsection{E) Objetivo finalista del Plan General de Turismo}

El objetivo finalista del Plan General del Turismo no es otro que la consolidación del turismo como sector clave para el desarrollo futuro de Andalucía, entendido como un sistema articulado de actividades con una importante capacidad para fomentar la sostenibilidad del medio ambiente y la identidad cultural de Andalucía, así como, para generar riqueza y empleo en la economía andaluza. En este sentido, el enunciado del Plan incide en la necesidad de que al Turismo le corresponda el máximo nivel de protagonismo en la estrategia global de desarrollo de Andalucía, debido al peso que tiene esta actividad dentro del conjunto de la economía andaluza; a su contrastada capacidad de generación de efectos de arrastre y, consiguientemente de generación 
de actividad y empleo inducido; y a las expectativas de crecimiento futuro de la actividad y de la posición de privilegio que Andalucía ocupa en el mercado nacional e internacional. ${ }^{33}$

\section{OBJETIVOS A CONSEGUIR POR EL PLAN GENERAL DEL TU- RISMO EN ANDALUCIA}

A nuestro juicio, tres son los objetivos a conseguir del Plan:

1. Andalucía como destino turístico integral: El Plan General de Turismo defiende la necesidad de mantener la actual línea promocional de la Consejería de Turismo y Deporte, que considera a Andalucía como "un destino turístico integral”. Además, se prestará una especial atención a las campañas que fomenten "una única imagen de calidad, que abarque al mismo tiempo la diversidad de productos y destinos turísticos”. A la promoción se destinarán 291,08 millones de euros, el $50,7 \%$ de la inversión total del Plan.

2. Ordenación de los recursos y del territorio: Además de las partidas correspondientes a la promoción, el Plan dedicará 167,66 millones de euros a las inversiones previstas en las políticas de ordenación de recursos turísticos y reequilibrio territorial. Este dinero se destinará a los programas sobre turismo rural, grandes ciudades, señalización turística, playas y comarcalización. En este sentido, también se abordará el desarrollo normativo de las zonas de preferente actuación turística integrada.

3. Fortalecimiento del empresariado y el empleo: El Plan General de Turismo se marca como una de sus grandes estrategias, el fortalecimiento del

\footnotetext{
${ }^{33}$ Para cumplir con estos fines se recogen trece estrategias de desarrollo, diez de las cuales cuentan en el documento con su correspondiente dotación económica, algunas de las cuales ya han sido expuestas anteriormente, y por tanto omito repetir la cantidad: Marco de consenso y cooperación con los agentes sociales; Coordinación entre las Administraciones Públicas; Integración y reconocimiento social del turismo; Ordenación de los recursos y reequilibrio territorial; Contribución a la creación y fortalecimiento del tejido empresarial y creación de empleo; Sostenibilidad. Presupuesto 2003-2006: 13.947.587 euros; Calidad. Presupuesto 2003-2006: 8.870.893 euros; Formación. Presupuesto 2003-2006: 8.308.188 euros; Tecnología e I+D. Presupuesto 2003-2006: 20.261.402 euros; Ordenación y diversificación de la oferta turística; Desestacionalización; Promoción; Contribución del turismo andaluz al desarrollo solidario. Presupuesto 2003-2006: 1.843.635 euros.
} 
tejido empresarial y la creación de empleo estable y de calidad. En este ámbito, el Plan prestará especial atención a las pequeñas y medianas empresas, a las iniciativas de asociacionismo empresarial y a los proyectos turísticos propiciados por mujeres y jóvenes. Además, se prevé la elaboración de un inventario de oportunidades en el exterior.

\section{REFLEXIÓN FINAL}

Como reflexión final del Plan General del Turismo de Andalucía podemos decir lo siguiente: Si efectivamente, todo lo que se propone conseguir desde el Plan General de Turismo llegara a ser realidad, estos avances ayudarán a convertir a Andalucía en uno de los destinos con mayor capacidad de adaptación y respuesta al escenario turístico del siglo XXI, cada vez más competitivo. Esto lo decimos desde el convencimiento de que, completar, es mejor que cambiar. Todo Plan se puede reducir a cifras. Casi 600 millones de euros de inversión hasta 2006 en la industria turística andaluza es un dato relevante. 